\title{
Daytime Ayahuasca administration modulates REM and slow-wave sleep in healthy volunteers
}

\author{
Manel J. Barbanoj • Jordi Riba • S. Clos • S. Giménez • \\ E. Grasa $\cdot$ S. Romero
}

Received: 2 May 2007 / Accepted: 19 September 2007 / Published online: 21 November 2007

(C) Springer-Verlag 2007

\begin{abstract}
Objectives Ayahuasca is a traditional South American psychoactive beverage and the central sacrament of Brazilianbased religious groups, with followers in Europe and the United States. The tea contains the psychedelic indole $N$, $N$-dimethyltryptamine (DMT) and $\beta$-carboline alkaloids with monoamine oxidase-inhibiting properties that render DMT orally active. DMT interacts with serotonergic neurotransmission acting as a partial agonist at $5-\mathrm{HT}_{1 \mathrm{~A}}$ and $5-\mathrm{HT}_{2 \mathrm{~A} / 2 \mathrm{C}}$ receptor sites. Given the role played by serotonin in the regulation of the sleep/wake cycle, we
\end{abstract}

Part of the results were presented in abstract form at the XIV Reunión Anual de la Asociación Ibérica de Patología del Sueño (AIPS), Almería, Spain, May 26-28, 2005 (Vigilia-Sueño 2005; 17: 49).

M. J. Barbanoj · J. Riba · S. Clos · S. Giménez • E. Grasa •

S. Romero

Centre d'Investigació del Medicament, Institut de Recerca,

Servei de Farmacologia Clínica, Hospital de la Santa Creu i Sant Pau, Barcelona, Spain

M. J. Barbanoj

Departament de Farmacologia i Terapèutica,

Universitat Autònoma de Barcelona,

Barcelona, Spain

S. Romero

Centre de Recerca en Enginyeria Biomèdica, Departament ESAII,

Universitat Politècnica de Catalunya,

Barcelona, Spain

M. J. Barbanoj $(\bowtie)$

Centre d'Investigació del Medicament,

Hospital de la Santa Creu i Sant Pau,

Sant Antoni M. Claret, 167,

08025 Barcelona, Spain

e-mail: mbarbanoj@santpau.es investigated the effects of daytime ayahuasca consumption in sleep parameters.

Measurements and results Subjective sleep quality, polysomnography (PSG), and spectral analysis were assessed in a group of 22 healthy male volunteers after the administration of a placebo, an ayahuasca dose equivalent to $1 \mathrm{mg}$ DMT $\mathrm{kg}^{-1}$ body weight, and $20 \mathrm{mg} d$-amphetamine, a proaminergic drug, as a positive control. Results show that ayahuasca did not induce any subjectively perceived deterioration of sleep quality or PSG-measured disruptions of sleep initiation or maintenance, in contrast with $d$ amphetamine, which delayed sleep initiation, disrupted sleep maintenance, induced a predominance of 'light' vs 'deep' sleep and significantly impaired subjective sleep quality. PSG analysis also showed that similarly to $d$ amphetamine, ayahuasca inhibits rapid eye movement (REM) sleep, decreasing its duration, both in absolute values and as a percentage of total sleep time, and shows a trend increase in its onset latency. Spectral analysis showed that $d$-amphetamine and ayahuasca increased power in the high frequency range, mainly during stage 2 . Remarkably, whereas slow-wave sleep (SWS) power in the first night cycle, an indicator of sleep pressure, was decreased by $d$-amphetamine, ayahuasca enhanced power in this frequency band.

Conclusions Results show that daytime serotonergic psychedelic drug administration leads to measurable changes in PSG and sleep power spectrum and suggest an interaction between these drugs and brain circuits modulating REM and SWS.

Keywords Ayahuasca $\cdot d$-amphetamine · Polysomnograpy Spectral analysis $\cdot$ Subjective evaluations .

Healthy volunteers 


\section{Introduction}

Ayahuasca is a psychotropic plant concoction that contains the psychedelic indole $N, N$-dimethyltryptamine (DMT) and has mind-modifying properties that have played a central role in shaping the world view of the indigenous peoples of the Amazon (Schultes and Hofmann 1987). The tea is commonly obtained by infusing the stems of the Banisteriopsis caapi liana together with the leaves of the Psychotria viridis bush, and it is used in traditional medicine and magico-religious practices (Schultes and Hofmann 1987). In recent times, several synchretic religions known generically as 'ayahuasca churches' have appeared in Brazil, blending Christian beliefs with the sacramental use of ayahuasca. These congregations have contributed significantly to the introduction of ayahuasca use to the United States and Europe. The US Supreme Court recently ruled in favor of allowing one of these churches, the União do Vegetal, the religious use of ayahuasca among its members, a status analogous to that held by the Native American Church for the use of peyote (Lophophora williamsii).

Research into ayahuasca has shown that the tea combines the orally labile DMT from $P$. viridis with monoamine oxidase (MAO)-inhibiting $\beta$-carboline alkaloids (Buckholtz and Boggan 1977b) from B. caapi in a single preparation. Remarkably, these $\beta$-carbolines block the metabolic breakdown of DMT by the visceral MAO, allowing its access to systemic circulation (Riba et al. 2003). In the central nervous system, ayahuasca interacts mainly with serotonergic neurotransmission, with DMT acting as a partial agonist at the $5-\mathrm{HT}_{1 \mathrm{~A}}$ and $5-\mathrm{HT}_{2 \mathrm{~A} / 2 \mathrm{C}}$ receptor sites (Deliganis et al. 1991).

In previous studies conducted by our group to characterise the pharmacology of ayahuasca, this tea showed a psychedelic and stimulatory profile compatible with $5-\mathrm{HT}_{2 \mathrm{~A}}$ agonism and pro-aminergic effects. Self-report questionnaires demonstrated somatic, perceptual and cognitive modifications, together with increases in positive mood and activation (Riba et al. 2003). Electroencephalography measures during wakefulness indicated reductions in slow (delta and theta) and alpha-2 activity (Riba et al. 2002) and measures of regional cerebral blood flow showed increased perfusion in paralimbic and frontal brain regions (Riba et al. 2006).

Sleep disturbances have been described for recreational drugs acting on serotonergic neurotransmission, such as 3,4 methylenedioxymethamphetamine (Morgan 2000). Serotonin plays a prominent role in the regulation of sleep-wake cycles. Both the firing of serotonergic neurons in the raphe nuclei and serotonin release increase during waking, decrease in non-REM sleep and are absent during the REM stage (McGinty and Harper 1976). This regulation mechanism is very complex and involves the interplay of several serotonin receptor subtypes, with $5-\mathrm{HT}_{1 \mathrm{~A}}$ agonism suppressing REM sleep (Driver et al. 1995), 5- $\mathrm{HT}_{2 \mathrm{~A}}$, 5- $\mathrm{HT}_{2 \mathrm{C}}$ antagonism enhancing slow-wave sleep (SWS) (Landolt et al. 1999) and 5-HT $2 \mathrm{C}$ agonism decreasing SWS (Katsuda et al. 1993).

In the present study, we investigated possible sleep disturbances associated with acute daytime ayahuasca administration. The sleep effects of daytime ayahuasca administration were compared vs placebo and vs $d$-amphetamine as a positive control. $d$-Amphetamine shares with ayahuasca stimulatory properties and an inhibitory effect on the waking EEG slow activity (delta and theta) but it lacks the psychedelic effects associated with serotonergic $5-\mathrm{HT}_{1 \mathrm{~A}}$ and $5-\mathrm{HT}_{2 \mathrm{~A} / 2 \mathrm{C}}$ agonism. Based on the arousing effects of ayahuasca, we postulated that a deterioration of sleep initiation, maintenance and subjective quality would be observed, similar to that previously reported for $d$-amphetamine (Saletu et al. 1989). However, given the pharmacological mechanism responsible for the psychedelic effects of DMT, i.e., 5- $\mathrm{HT}_{2 \mathrm{~A}}$ agonism, we also postulated that ayahuasca would modulate REM and slow-wave sleep.

\section{Materials and methods}

\section{Volunteers}

Twenty-two young healthy male volunteers were recruited. Mean age was 27.1 years (range 20-38), mean weight was $67.6 \mathrm{~kg}$ (range 60-85) and mean height was $1.77 \mathrm{~m}$ (range 1.60-1.90). Eligibility criteria included prior use of psychedelics on at least ten occasions without sequelae derived thereof. The most frequently consumed psychedelics were LSD and psilocybian mushrooms. All volunteers underwent a structured psychiatric interview (DMS-IV). Exclusion criteria included current or past history of Axis-I disorders and alcohol or other substance dependence. A medical examination and laboratory tests were performed before study initiation. All participants were screened for sleep disturbances (Pittsburg sleep quality index $<5$ ). Pre-study examinations also included drug screening and serological testing (for hepatitis B and C and HIV). The alcohol, coffee and cigarette consumption reported in all volunteers was insufficient to lead to withdrawal symptoms during the 48$\mathrm{h}$ period around the experimental session where consumption was not allowed ( $\leq 39 \mathrm{~g}$ absolute alcohol/day, $\leq 100 \mathrm{mg}$ caffeine/day, $\leq 5$ cigarettes/day). No strenuous physical exercise or naps were allowed in the $24 \mathrm{~h}$ before each experimental session or in the ensuing $24 \mathrm{~h}$. Participants were requested not to take any medications or illicit drugs during the study and were asked to keep regular sleepwake habits during the fortnight before the study and 
during the study proper. Urine was tested for illicit drug use on each experimental session.

The study was approved by the local Ethics Committee and the Spanish Ministry of Health, and was conducted following the principles stated in the Declaration of Helsinki and the guidelines of Good Clinical Practice. All volunteers gave their written informed consent to participate.

\section{Drugs}

The administered drugs were a placebo, $20 \mathrm{mg} d$-amphetamine and a freeze-dried encapsulated formulation of ayahuasca equivalent to $1 \mathrm{mg} \mathrm{DMT} / \mathrm{kg}$ body weight. One gram of lyophilizate contained: $8.33 \mathrm{mg}$ DMT, $14.13 \mathrm{mg}$ harmine, $0.96 \mathrm{mg}$ harmaline and $11.36 \mathrm{mg}$ tetrahydroharmine (THH) per gram. The calculated individual dose of ayahuasca for each volunteer was administered by combining gelatine capsules $(00$ size $)$ containing $0.5,0.25$ or $0.125 \mathrm{~g}$ of lyophilizate. Volunteers received the same number of capsules on each experimental session.

\section{Study design}

The study was conducted according to a randomized, double-blind, placebo-controlled, cross-over design and involved participation in three experimental sessions at least 1 week apart, plus an adaptation night in the sleep laboratory. The adaptation night was used to familiarize the participants with the laboratory and the recording procedures and was held within the 2 weeks before the first experimental session. Data from this adaptation night were not included in the statistical analyses. On each of the three experimental sessions, volunteers arrived in the laboratory at 7:00 A.M. and had a light breakfast before 10:00 A.M. At 12:00 noon, they received the capsules containing one of the three treatments and they then remained in the laboratory until 12:00 the next day. Volunteers were constantly supervised and they were not allowed to nap. Sleep recordings were conducted from 11:00 P.M. of the experimental session until 7:00 A.M. of the next day. Data from these three nights were subsequently submitted to statistical analysis. Additionally, to measure pattern and intensity of the acute subjective effects induced by ayahuasca during the day, participants responded selfreport questionnaires before and after $4 \mathrm{~h}$ of drug administration (see below).

Subjective effect measures

Self-rated subjective effects were measured by administering Spanish versions of the Hallucinogen Rating Scale or HRS (Riba et al. 2001) and the Addiction Research Center
Inventory or ARCI (Lamas et al. 1994). The HRS measures psychedelic-induced subjective effects and includes six scales: somaesthesia, reflecting somatic effects; affect, sensitive to emotional and affective responses; volition, indicating the volunteer's capacity to willfully interact with his/her 'self' and/or the environment; cognition, describing modifications in thought processes or content; perception, measuring visual, auditory, gustatory and olfactory experiences; and finally intensity, which reflects the strength of the overall experience. The range of scores for all HRS scales is 0 to 4 . The ARCI consists of five scales or groups: MBG, morphine-benzedrine group, measuring euphoria and positive mood; PCAG, pentobarbital-chlorpromazinealcohol group, measuring sedation; LSD, lysergic acid diethylamide scale, measuring somatic-dysphoric effects; $\mathrm{BG}$, the benzedrine group, measuring intellectual energy and efficiency, and the A scale, an empirically derived scale measuring amphetamine-like effects. The range of scores is 0 to 16 for MBG, -4 to 11 for PCAG, -4 to 10 for LSD, -4 to 9 for $\mathrm{BG}$ and 0 to 11 for $\mathrm{A}$. Volunteers answered the ARCI immediately before drug administration, and $4 \mathrm{~h}$ after drug intake, whereas the HRS was only answered at $4 \mathrm{~h}$ post-administration.

Before statistical analysis, ARCI scores were transformed to differences from pre-administration values. The transformed ARCI scores and raw HRS scores were analyzed by means of multivariate and univariate tests as indicated below.

\section{Recordings and sleep stage classification}

Sleep recordings were performed in individual, soundattenuated, temperature-regulated rooms and volunteers were supervised by qualified technical staff. Volunteers had dinner by 8.00 P.M. and started sleep procedures. The total time in bed was fixed at $8 \mathrm{~h}$. The lights were turned off around 11.00 P.M. and turned on around 7 A.M. the next morning. In addition, the volunteers completed a self-rating scale on the subjective quality of sleep and awakening no later than $15 \mathrm{~min}$ after having woken up each morning (Saletu et al. 1987).

Data were acquired by means of either (1) the Coherence 32E-Deltamed system, or (2) the SleepLab-Aequitron Medical Recordings system; the same system was used for each volunteer. Recordings consisted of six EEGchannels (Fp1, Fp2, C3, C4, O1, O2, vs the average of both mastoids (A1-A2) according to the 10/20 International System), two electro-oculographic leads (EOG) (right and left, registered between both external canthi, with a capacity to detect ocular movements in both directions: horizontal and vertical), and one chin electromyographic channel (EMG), consisting of two electrodes placed on the submentonian muscles, which monitored the muscular tone. 
Three channels were included to monitor the respiratory function: one for airflow signal (by means of a thermistor placed in the path of airflow from nose and mouth) and two channels to record rib cage and abdominal motion (by calibrated transducers). Finally, two channels (linked electrodes on the left and right anterior tibialis) were used to register limb movements. EEG and EOG channels were filtered to a bandwidth of $0.1-75 \mathrm{~Hz}$ with a sensitivity of $10 \mu \mathrm{V} / \mathrm{mm}$. EMG was filtered to a bandwidth of $10-75 \mathrm{~Hz}$ with a sensitivity of $5 \mu \mathrm{V} / \mathrm{mm}$. A $50-\mathrm{Hz}$ notch filter was used to attenuate electrical noise. The electrodes were goldplated. Channels were calibrated before each recording and the electrode impedance was kept below $10 \mathrm{k} \Omega$.

The sleep recordings were visually scored in a 30 -s epoch resolution according to the traditional standard R\&K criteria (Rechtschaffen and Kales 1968) using the View and Rate (Cdatentechnik GbR, (C) 1995-1999 3.02 version) program. Analysis was performed by two independent sleep scorers. Discrepancies were solved by a third expert from the same laboratory. Each scorer was blind to the other raters' analysis and treatment received by the participant.

Sleep variables were derived by visual scoring using standard criteria. Total sleep time (TST) is the amount of actual sleep time in the total sleep period (TSP); equal to TSP less wakefulness (stage 0). TSP is the total time available for sleep during an attempt to sleep and comprises NREM and REM sleep, as well as wakefulness; in addition to TST, TSP includes stage 0 . The number of awakenings refers to the arousals to wakefulness during TSP. The sleep efficiency index (SEI) is the proportion of sleep in the recorded period, and is calculated by dividing TST by the total time in bed (TIB) and multiplied by 100 . Sleep stages 1, 2, slow-wave sleep (3+4) (SWS) and REM are expressed in minutes and in percentages of the TST. Movement time is identified when more than a half of the scoring epoch is obscured because of movement but the preceding and subsequent epochs are of sleep. Movement time is expressed in minutes and in percentage of the TST. Latency to stages 1, 2 and 3 defines the period of time measured from lights out to the appearance of sleep stages 1,2 and 3, respectively. REM latency is defined as clock time from the first epoch of stage 2 (followed by $\geq 8$ min sleep in the next $10 \mathrm{~min}$ ) to the first REM period of at least $3 \mathrm{~min}$. In addition, the number of NREM and REM periods as well as the average duration of NREM and REM periods and of sleep cycles was computed. Consecutive NREM-REM cycles were defined according to modifications of the criteria proposed by Feinberg and Floyd (1979). NREM episodes were defined as starting with stage 2 , containing at least 15 min of stages 2, 3 and 4, and being followed by REM episodes of at least 5-min duration. No minimal criterion for the REM duration was applied for the completion of the first cycle.
EEG power spectra

Despite its widespread use in visual scoring, the conventional R\&K criteria (Rechtschaffen and Kales 1968) provides insufficient information about the continuity of sleep stages. All-night spectral analysis is a sensitive method for documenting pharmacological effects on sleep EEG (Borbély et al. 1985). It not only detects shifts between the various sleep stages during the night, but also takes into account the qualitative alterations of certain stages (Schlösser et al. 1998). To conduct spectral analysis, the EEG signal was high-pass $(0.3 \mathrm{~Hz})$ and low-pass $(35 \mathrm{~Hz})$ filtered before being converted from analogue to digital and the sampling frequency was $256 \mathrm{~Hz}$. Power spectra of 5-s artefact-free epochs, weighted by a Hanning window, were computed using the Fast Fourier Transform and matched with the sleep scores. Epochs containing artefacts caused either by saturation or muscle activity were automatically identified and eliminated. Mean $( \pm$ SEM $)$ artefact-free recordings, in seconds, computed for the different experimental nights were: $5.245 \pm 50.3$ after placebo, 5.335 \pm 30.9 after ayahuasca, and 5.024 \pm 88.2 , after $d$-amphetamine, being $91.4,93.1$ and $87.7 \%$ of the corresponding TIB, respectively. Power density values (C4A1 derivation) were averaged into $0.4 \mathrm{~Hz}(0.2-$ $6.0 \mathrm{~Hz})$ and $0.8 \mathrm{~Hz}(6.2-26.0 \mathrm{~Hz})$ bins. The spectra were calculated separately for non-REM sleep (NREMS stages: $1,2,3$ and 4), stage 2 (S2), slow wave activity (SWS: stages 3 and 4) and REM sleep (REMS).

Dynamics of slow-wave activity, spindle frequency activity during whole night and delta EOG activity during REM sleep

Slow-wave activity (SWA) is defined as the power in the delta band $(0.5-4.0 \mathrm{~Hz})$ and spindle frequency activity (SFA) as the power in the sigma band $(11.0-15.0 \mathrm{~Hz})$ for the C4A1 derivation during whole night sleep. Delta EOG activity (DEA) is defined as the power in the delta band $(0.5-4.0 \mathrm{~Hz})$ for the EOG channels during REM sleep. These variables were computed from 5 -s artifact-free epochs. DEA was used as a representative of phasic REM activity intensity. A moving average estimation of 5-min duration was computed to smooth the signal throughout the night.

To compensate for the individual differences in the occurrence and duration of the NREM-REM cycles, a method derived from that of Aeschbach and Borbély was used (Aeschbach and Borbély 1993). For SWA and SFA, each NREM period of unequal length was subdivided into 24 equal parts, and each REM period into four equal parts. They were then averaged across subjects. 
For DEA, each REM period of unequal length was subdivided into 24 equal parts and averaged across subjects. Changes in the three dynamic activities were evaluated on the raw data by calculating areas under the curve (AUC) in each cycle.

Sleep and awakening quality self-rating scale

A Spanish version of the 'Self-assessment Scale for Sleep and Awakening Quality (SSA)' (Saletu et al. 1987) was used. The SSA consists of 20 items grouped in three categories: (1) SSA-1 (seven items), which evaluates subjective sleep quality; (2) SSA-2 (eight items), evaluating subjective awakening quality; and (3) SSA-3 (five items), evaluating the presence of somatic complaints. Responses are coded according to an ordinal scale with four possibilities (not at all, slightly, moderately and extremely). In the coding process, the values $1,2,3$ or 4 are assigned in such a way that a higher score means a worse subjective quality, with the theoretical score ranging from: 20-80 for the global scale (SSA), 7-28 for SSA-1, 8-32 for SSA-2 and 5-20 for SSA-3. Furthermore, the questionnaire presents five additional open questions related to different moments of the night, from which subjective sleep latency (SSL) and subjective sleep efficiency (SSE) are calculated.

\section{Statistical analysis}

To decrease the risk of type I error, PSG variables were grouped in three different clusters comprising: (1) sleep initiation and maintenance variables; (2) sleep architecture variables; and (3) NREM-REM period variables. SSA variables were grouped in a fourth cluster. Each cluster and a subjective effect measures cluster obtained from the selfreport questionnaires (HRS and ARCI combined) were subjected to a multivariate analysis of variance (MANOVA). Within each cluster, the MANOVA yielded the result of a general linear model with one within-subject factor (treatment: three levels) for each variable. Greenhouse-Geisser $\varepsilon$ correction was used. Pairwise comparisons were conducted by means of repeated measures $t$ tests corrected for multiple comparisons (Sidak).

To assess the effects on EEG power spectra at the different sleep stages and on the AUCs of its dynamics, repeated measures $t$ tests were applied to each frequency bin or AUC, respectively, comparing placebo with each active treatment.

Differences were considered significant when the probability of type I error was less than 0.05 (two-sided).

\section{Results}

Final study population

Because of technical problems during the acquisition phase (electrode failure at some time point during the sleep recording), the data from four subjects had to be excluded from the analysis, leaving a final sample of 18 with a complete set of PSG recordings. No significant differences in demographic characteristics were observed between the initial and the final sample. All 18 participants completed the trial and were compliant with the study protocol, and all active treatments were well tolerated.

\section{Subjective effect measures}

Significant results were observed for subjective effects as measured by self-report questionnaires (Pillai's trace: 1.45; $F=5.98, d f=22,50 ; p<0.001)$. Results for the individual subscales are shown in Table 1.

\section{PSG variables}

\section{Sleep initiation and maintenance}

Significant results were observed for sleep initiation and maintenance variables (Pillai's trace: $1.14 ; F=3.10, d f=20$, 52; $p=0.001)$. Significant results were observed for all sleep latencies. $d$-Amphetamine induced significant increases in latencies to stage 1, stage 2, and REM compared to placebo and to ayahuasca. Additionally, it showed a trend to increase stage 3 latency. In contrast, ayahuasca only showed a tendency to increase REM latency compared to placebo (Table 2).

Sleep maintenance variables also showed significant results. $d$-Amphetamine induced significant decreases in TSP, TST and SEI and significant increases in stage 0, total wake time and awakenings/TSP as compared to either placebo or ayahuasca. Ayahuasca did not differ from placebo in any of these variables (Table 2).

\section{Sleep architecture}

Significant results were observed for sleep architecture variables (Pillai's trace: $1.28 ; F=4.60, d f=20,52$; $p<0.001)$. Duration of all sleep stages showed significant effects except for SWS in percentage of TST and movement time (in minutes and percentage of TST). Compared to placebo and ayahuasca, $d$-amphetamine induced significant decreases in REM as measured in minutes or as percentage of TST. Significant decreases in SWS and significant increases in stage 1 sleep were also seen after $d$-amphetamine but only when the former was 
Table 1 Acute subjective effects induced by placebo, ayahuasca $1 \mathrm{mg}$ DMT/kg and $d$-amphetamine $20 \mathrm{mg}$

\begin{tabular}{|c|c|c|c|c|c|c|c|}
\hline & \multirow[t]{2}{*}{ Placebo } & \multirow[t]{2}{*}{ Ayahuasca } & \multirow[t]{2}{*}{$d$-Amphetamine } & \multirow[t]{2}{*}{ GLM ( $p$ values) } & \multicolumn{3}{|c|}{ Adjusted for multiple paired comparisons: Sidak } \\
\hline & & & & & PLA:AYA & PLA:AMP & AYA:AMP \\
\hline \multicolumn{8}{|l|}{ HRS } \\
\hline Somaesthesia & $0.03(0.07)$ & $1.36(0.73)$ & $0.56(0.44)$ & $<0.001$ & $* * *$ & $* * *$ & $* * *$ \\
\hline Affect & $0.33(0.19)$ & $1.43(0.60)$ & $0.72(0.33)$ & $<0.001$ & $* * *$ & $* * *$ & $* * *$ \\
\hline Perception & $0.01(0.04)$ & $1.61(0.89)$ & $0.12(0.17)$ & $<0.001$ & $* * *$ & & $* * *$ \\
\hline Cognition & $0.02(0.07)$ & $1.45(1.07)$ & $0.34(0.35)$ & $<0.001$ & $* * *$ & $* *$ & $* * *$ \\
\hline Volition & $0.78(0.63)$ & $1.77(0.69)$ & $0.88(0.39)$ & $<0.001$ & $* * *$ & & $* *$ \\
\hline Intensity & $0.06(0.16)$ & $2.25(0.97)$ & $1.10(0.79)$ & $<0.001$ & $* * *$ & $* * *$ & $* * *$ \\
\hline \multicolumn{8}{|l|}{ ARCI } \\
\hline A & $0.11(1.18)$ & $3.06(1.59)$ & $2.22(1.93)$ & $<0.001$ & $* * *$ & $* *$ & \\
\hline BG & $0.33(1.19)$ & $-0.17(1.95)$ & $2.83(2.77)$ & $<0.001$ & & $* *$ & $* *$ \\
\hline MBG & $0.06(1.86)$ & $3.11(3.68)$ & $3.33(2.74)$ & 0.008 & $*$ & $* *$ & \\
\hline PCAG & $-0.89(3.83)$ & $0.06(3.28)$ & $-3.72(3.32)$ & 0.007 & & & $*$ \\
\hline LSD & $0.06(1.39)$ & $4.61(2.59)$ & $2.50(1.62)$ & $<0.001$ & $* * *$ & $* *$ & $*$ \\
\hline
\end{tabular}

Means (SD) of the scores obtained for the HRS and ARCI questionnaires subscales $(n=18)$, and results of the statistical analysis performed. $P L A$ placebo, $A Y A$ ayahuasca, $A M P d$-amphetamine, $A$ amphetamine, $B G$ benzedrine group, $M B G$ morphine-benzedrine group, $P C A G$ pentobarbital-chlorpromazine-alcohol group, $L S D$ lysergic acid diethylamide scale $* p<0.05$

$* * p<0.01$

$* * * p<0.001$

measured in minutes and the latter in percentage. In addition, $d$-amphetamine produced significant effects on stage 2. An increase was found when measured in minutes, but when expressed as percentage, this difference was only observed in relation to placebo. Ayahuasca's significant effects as compared to placebo consisted in decreases in REM (in minutes and percentage of TST). A tendency to increase stage 2 (in minutes and percentage of TST) was also observed (Table 3 ).

\section{NREM-REM periods}

Significant results were observed for NREM-REM period variables (Pillai's trace: $0.89 ; F=4.97, d f=10,62$; $p<0.001)$. The number of NREM and REM periods as well as the average duration of NREM periods and sleep cycles showed significant differences between treatments. Both active compounds, $d$-amphetamine and ayahuasca, decreased the number of periods and increased the duration

Table 2 Sleep initiation and maintenance after daytime administration of ayahuasca $1 \mathrm{mg}$ DMT/kg and $d$-amphetamine $20 \mathrm{mg}$

\begin{tabular}{|c|c|c|c|c|c|c|c|}
\hline & \multirow[t]{2}{*}{ Placebo } & \multirow[t]{2}{*}{ Ayahuasca } & \multirow[t]{2}{*}{$d$-Amphetamine } & \multirow[t]{2}{*}{ GLM ( $p$ values) } & \multicolumn{3}{|c|}{$\begin{array}{l}\text { Adjusted for multiple paired } \\
\text { comparisons: Sidak }\end{array}$} \\
\hline & & & & & PLA:AYA & PLA:AMP & AYA:AMP \\
\hline Latency to stage 1 (minutes) & $19.39 \pm 5.01$ & $13.78 \pm 2.64$ & $91.42 \pm 16.51$ & $<0.001$ & & $* * *$ & $* * *$ \\
\hline Latency to stage 2 (minutes) & $21.58 \pm 5.30$ & $16.97 \pm 3.38$ & $109.29 \pm 19.82$ & $<0.001$ & & $* * *$ & $* * *$ \\
\hline Latency to stage 3 (minutes) & $21.86 \pm 4.00$ & $17.11 \pm 2.00$ & $62.89 \pm 18.93$ & 0.035 & & & $*$ \\
\hline REM latency (minutes) & $92.44 \pm 8.65$ & $113.72 \pm 10.55$ & $210.27 \pm 18.91$ & $<0.001$ & $*$ & $* * *$ & $* *$ \\
\hline Total sleep period (minutes) & $458.72 \pm 5.35$ & $463.56 \pm 2.95$ & $361.06 \pm 22.22$ & $<0.001$ & & $* * *$ & $* * *$ \\
\hline Total sleep time (minutes) & $444.67 \pm 6.48$ & $450.14 \pm 3.99$ & $297.97 \pm 24.05$ & $<0.001$ & & $* * *$ & $* * *$ \\
\hline Sleep efficiency (\%) & $92.52 \pm 1.37$ & $93.87 \pm 0.83$ & $61.94 \pm 4.98$ & $<0.001$ & & $* * *$ & $* * *$ \\
\hline Wake (minutes) & $19.67 \pm 5.05$ & $14.42 \pm 2.79$ & $116.58 \pm 21.79$ & $<0.001$ & & $* * *$ & $* * *$ \\
\hline Stage 0 (minutes) & $13.72 \pm 3.30$ & $13.03 \pm 2.70$ & $62.94 \pm 13.01$ & $<0.001$ & & $* *$ & $* * *$ \\
\hline Awakenings/TSP & $3.01 \pm 0.73$ & $2.81 \pm 0.59$ & $18.48 \pm 4.12$ & 0.001 & & $* *$ & $* *$ \\
\hline
\end{tabular}

Mean \pm SEM $(n=18)$

PLA Placebo, AYA ayahuasca, AMP d-amphetamine

${ }^{*} p<0.10$

$* * p<0.01$

$* * * p<0.001$ 
Table 3 Sleep architecture after daytime administration of ayahuasca $1 \mathrm{mg}$ DMT/kg and $d$-amphetamine $20 \mathrm{mg}$

\begin{tabular}{|c|c|c|c|c|c|c|c|}
\hline & \multirow[t]{2}{*}{ Placebo } & \multirow[t]{2}{*}{ Ayahuasca } & \multirow[t]{2}{*}{$d$-Amphetamine } & \multirow[t]{2}{*}{ GLM ( $p$ values) } & \multicolumn{3}{|c|}{$\begin{array}{l}\text { Adjusted for multiple paired comparisons: } \\
\text { Sidak }\end{array}$} \\
\hline & & & & & PLA:AYA & PLA:AMP & AYA:AMP \\
\hline Stage 1 (minutes) & $15.44 \pm 2.48$ & $14.44 \pm 2.61$ & $21.53 \pm 3.54$ & 0.024 & & & $*$ \\
\hline Stage $1(\%)$ & $3.48 \pm 0.57$ & $3.25 \pm 0.61$ & $8.08 \pm 1.33$ & $<0.001$ & & $* * * *$ & $* * * *$ \\
\hline Stage 2 (minutes) & $239.58 \pm 9.22$ & $261.83 \pm 8.37$ & $180.39 \pm 17.60$ & $<0.001$ & $*$ & $* * *$ & $* * * *$ \\
\hline Stage $2(\%)$ & $53.71 \pm 1.64$ & $58.09 \pm 1.68$ & $59.77 \pm 2.39$ & 0.015 & $*$ & $* *$ & \\
\hline SWS (minutes) & $86.03 \pm 3.88$ & $83.94 \pm 6.06$ & $58.50 \pm 5.51$ & $<0.001$ & & $* * *$ & $* * * *$ \\
\hline SWS (\%) & $19.40 \pm 0.93$ & $18.67 \pm 1.37$ & $20.50 \pm 1.88$ & 0.572 & & & \\
\hline REM (minutes) & $98.28 \pm 4.57$ & $82.42 \pm 4.14$ & $33.42 \pm 5.48$ & $<0.001$ & $* * *$ & $* * * *$ & $* * * *$ \\
\hline REM (\%) & $22.19 \pm 1.08$ & $18.32 \pm 0.93$ & $10.21 \pm 1.63$ & $<0.001$ & $* * *$ & $* * * *$ & $* * * *$ \\
\hline Movement time (minutes) & $5.81 \pm 0.94$ & $4.61 \pm 0.68$ & $4.14 \pm 0.82$ & 0.061 & & & \\
\hline Movement time (\%) & $1.32 \pm 0.21$ & $1.02 \pm 0.15$ & $1.44 \pm 0.28$ & 0.095 & & & \\
\hline
\end{tabular}

All percentages are expressed relative to total sleep time (TST). Mean \pm SEM $(n=18)$.

PLA Placebo, AYA ayahuasca, AMP d-amphetamine

${ }^{*} p<0.10$

$* * p<0.05$

$* * * p<0.01$

$* * * * p<0.001$

of NREM periods and sleep cycles as compared to placebo. However, $d$-amphetamine's effects were significantly larger than those obtained after ayahuasca (Table 4).

Spectral analysis

\section{EEG power spectra}

The mean all-night power spectra are presented in Fig. 1. The values for nights after an active treatment are expressed as a percentage of the placebo night.
The NREM power spectrum showed differences as a function of the active compound. Compared to placebo, values were significantly higher after $d$-amphetamine in the high-frequency range (frequencies higher than $15 \mathrm{~Hz}$ ), while after ayahuasca, significantly higher values were limited to the $15-20 \mathrm{~Hz}$ frequency band. The spectrum in stage 2 was very similar to that of NREM, but the SWA spectrum showed no significant differences between placebo and the active compounds. In REM, power density was significantly reduced in comparison to placebo after $d$-amphetamine in the 2.4-2.8 and 5.6-8.4 Hz frequency ranges.

Table 4 NREM-REM periods after daytime administration of ayahuasca $1 \mathrm{mg}$ DMT/kg and $d$-amphetamine $20 \mathrm{mg}$

\begin{tabular}{|c|c|c|c|c|c|c|c|}
\hline & \multirow[t]{2}{*}{ Placebo } & \multirow[t]{2}{*}{ Ayahuasca } & \multirow[t]{2}{*}{$d$-Amphetamine } & \multirow[t]{2}{*}{ GLM ( $p$ values) } & \multicolumn{3}{|c|}{$\begin{array}{l}\text { Adjusted for multiple } \\
\text { paired comparisons: Sidak }\end{array}$} \\
\hline & & & & & PLA:AYA & PLA:AMP & AYA:AMP \\
\hline Number NREM periods & $4.06 \pm 0.17$ & $3.61 \pm 0.14$ & $1.72 \pm 0.18$ & $<0.001$ & $*$ & $* * *$ & $* * *$ \\
\hline Number REM periods & $4.06 \pm 0.17$ & $3.61 \pm 0.14$ & $1.56 \pm 0.23$ & $<0.001$ & $*$ & $* * *$ & $* * *$ \\
\hline $\begin{array}{l}\text { Average duration NREM } \\
\text { periods (minutes) }\end{array}$ & $82.20 \pm 4.13$ & $95.34 \pm 3.84$ & $146.51 \pm 13.18$ & $<0.001$ & $* *$ & $* * *$ & $* *$ \\
\hline $\begin{array}{l}\text { Average duration REM } \\
\text { periods (minutes) }\end{array}$ & $26.46 \pm 1.39$ & $29.64 \pm 3.44$ & $19.94 \pm 3.30$ & 0.051 & & & \\
\hline $\begin{array}{l}\text { Average duration sleep } \\
\text { cycles (minutes) }\end{array}$ & $110.92 \pm 4.28$ & $123.12 \pm 4.10$ & $210.23 \pm 18.92$ & $<0.001$ & $*$ & $* * *$ & $* * *$ \\
\hline
\end{tabular}

Mean \pm SEM $(n=18)$

PLA Placebo, AYA ayahuasca, AMP $d$-amphetamine

$* p<0.05$

$* * p<0.01$

$* * * p<0.001$ 
Fig. 1 EEG power density (C4A1-derivation) in non-REM sleep (stages 1, 2, 3 and 4) stage 2 (S2), slow-wave sleep (stages 3 and 4) and REM sleep after daytime administration of ayahuasca $1 \mathrm{mg} \mathrm{DMT} / \mathrm{kg}$ and $d$ amphetamine $20 \mathrm{mg}$. For each frequency bin $(n=18)$, means are expressed as a percentage of the corresponding value after placebo (horizontal dashed lines at $0 \%)$. Asterisks at the bottom of the panels indicate frequency bins which differ significantly from placebo $(p<0.05, t$ test for repeated measures)
AYAHUASCA
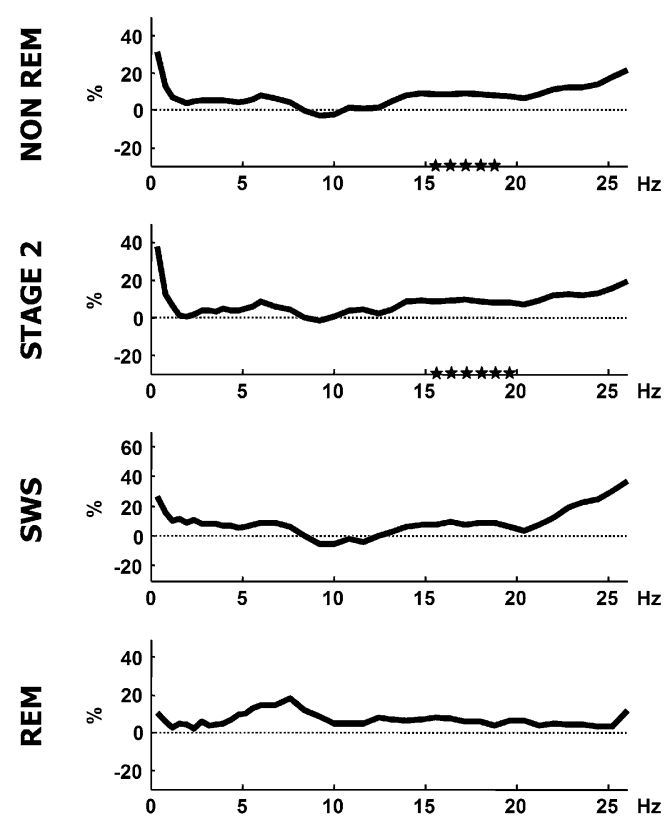

d-AMPHETAMINE
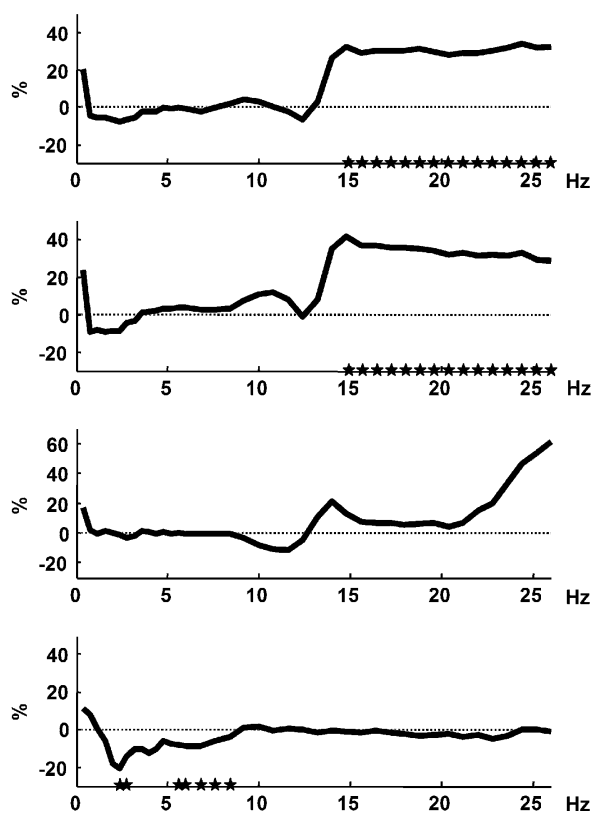

Dynamics of slow-wave activity

On all nights, either after placebo or active drugs, SWA was higher in NREM episodes and lower in REM episodes, and a declining trend was observed over consecutive NREM episodes. The dynamics of SWA throughout the night after all experimental interventions is presented in Fig. 2. A significant reduction in SWA after $d$-amphetamine relative to placebo was obtained in the first cycle $(t=2.41, d f=14$, $p=0.030)$. On the contrary, a trend to increase SWA between ayahuasca and placebo in the first cycle was also evidenced ( $t=1.82, d f=17, p=0.086)$.

As it has been shown that the delta power in a cycle is dependent on the number of cycles in that night (Preud'homme et al. 2000), it has been proposed that to avoid a potential bias, cycle-by-cycle comparisons should be conducted on nights with the same number of cycles. As the number of sleep cycles was significantly affected by the active treatments, a reanalysis was performed incorporating only those volunteers who showed the same number of cycles after all three treatments. No such analysis could be performed after $d$-amphetamine as all subjects had a lower number of cycles in relation to placebo. However, eight subjects presented the same number of cycles after ayahuasca and placebo. In this subgroup of volunteers, SWA showed a significant increase in activity after ayahuasca as compared to placebo. This increase was clearly circumscribed to the first cycle $(t=2.78, d f=7$, $p=0.027$ ).

\section{Dynamics of spindle frequency activity}

The typical pattern of SFA with low values in REM episodes, and a higher level, U-shaped pattern (with lowest values coinciding with highest values of SWA) in NREM episodes, was observed after all three treatments. No significant changes were observed in the amount of SFA between any active treatment and placebo (Fig. 2).

Dynamics of slow activity in EOG channels (DEA) during REM sleep

Slow activity in EOG channels during REM sleep did not show any significant changes when comparing the night after placebo with the nights after active compounds.

Subjective sleep and awakening quality

Significant results were observed for subjective sleep and awakening quality variables (Pillai's trace: $0.81 ; F=4.21$, $d f=10,62 ; p<0.001)$. No significant treatment effects were observed for somatic complaints. However, after $d$-amphetamine, there was a significant impairment of the global score and the subjective sleep quality score in comparison to placebo and ayahuasca. Significant effects were also obtained in subjective sleep latency and subjective sleep efficiency. $d$-Amphetamine induced an increase of the former and a decrease of the latter in comparison to placebo and ayahuasca (Table 5). 
AYAHUASCA
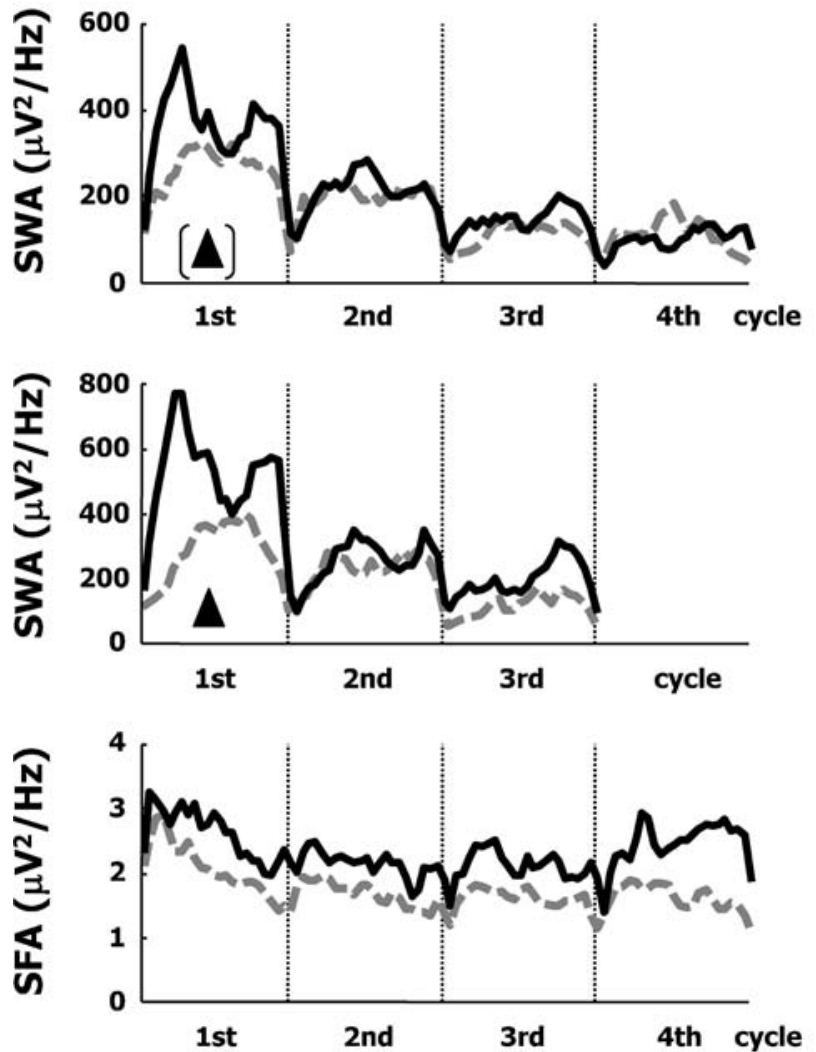

d-AMPHETAMINE

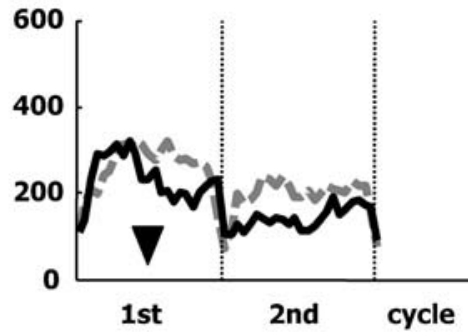

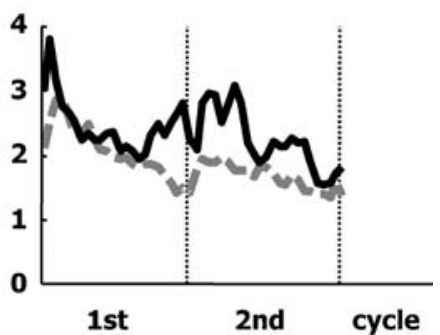

Fig. 2 Time course of EEG slow-wave activity (SWA, 0.5-4.0 Hz range; C4-A1-derivation) and spindle frequency activity (SFA, 11.0 $15.0 \mathrm{~Hz}$ range; C4-A1-derivation) plotted after daytime administration of ayahuasca $1 \mathrm{mg}$ DMT/ $\mathrm{kg}$ and $d$-amphetamine $20 \mathrm{mg}$ (continuous curves) against placebo (dashed curves). For each subject, individual NREM episodes were subdivided into 20 equal time bins. Data were averaged across subjects ( $n=18$, for ayahuasca and $n=14$ for $d$ amphetamine) and plotted against the mean timing of NREM sleep.

Dashed vertical lines delimit NREM episodes. Triangles indicate significant AUC increases or decreases in relation to placebo for a given NREM episode. Ayahuasca showed a trend increase in the first NREM episode ( $t$ test for repeated measures: $p=0.086$; upper left panel), which became significant $(p=0.027)$ when the analysis was performed with only those volunteers who showed the same number of cycles after ayahuasca and placebo ( $n=8$; middle panel)

Table 5 Subjective sleep and awakening quality after daytime administration of ayahuasca $1 \mathrm{mg}$ DMT/kg and $d$-amphetamine $20 \mathrm{mg}$

\begin{tabular}{|c|c|c|c|c|c|c|c|}
\hline & \multirow[t]{2}{*}{ Placebo } & \multirow[t]{2}{*}{ Ayahuasca } & \multirow[t]{2}{*}{$d$-Amphetamine } & \multirow[t]{2}{*}{ GLM ( $p$ values) } & \multicolumn{3}{|c|}{ Adjusted for multiple paired comparisons: Sidak } \\
\hline & & & & & PLA:AYA & PLA:AMP & AYA:AMP \\
\hline SSA-T & $34.67 \pm 1.22$ & $33.72 \pm 1.02$ & $41.44 \pm 1.60$ & $<0.001$ & & $* *$ & * \\
\hline SSA-1 & $13.89 \pm 0.64$ & $14.28 \pm 0.73$ & $19.67 \pm 0.85$ & $<0.001$ & & $* *$ & $* *$ \\
\hline SSA-2 & $15.28 \pm 0.76$ & $13.94 \pm 0.50$ & $16.11 \pm 0.85$ & 0.047 & & & \\
\hline SSA-3 & $5.50 \pm 0.20$ & $5.50 \pm 0.23$ & $5.67 \pm 0.24$ & 0.715 & & & \\
\hline SSL (minutes) & $31.56 \pm 5.80$ & $37.33 \pm 7.52$ & $115.22 \pm 18.19$ & $<0.001$ & & * & * \\
\hline SSE (minutes) & $85.64 \pm 3.02$ & $85.43 \pm 2.52$ & $59.25 \pm 5.64$ & $<0.001$ & & $* *$ & $* *$ \\
\hline
\end{tabular}

Mean $\pm \operatorname{SEM}(n=18)$

$S S A$ Self-assessment scale for sleep and awakening quality: $T=$ total score, 1 subjective sleep quality, 2 subjective awakening quality, 3 somatic complains; SSL subjective sleep latency, SSE subjective sleep efficiency, PLA placebo, AYA ayahuasca, AMP $d$-amphetamine

$*_{p}<0.01$

$* * p<0.001$ 


\section{Discussion}

Daytime drug administration in the present study caused significant psychotropic effects as measured by self-report questionnaires. $d$-Amphetamine showed a pattern typical of the psychostimulants with high scores in the ARCI-A, ARCI-BG and ARCI-MBG subscales (Martin et al. 1971). Similarly, ayahuasca showed significant effects in the ARCI-A and ARCI-MBG subscales, which measure amphetamine-like stimulatory effects and euphoria, respectively, but not in the ARCI-BG which measures intellectual efficiency. Both drugs induced somatic-dysphoric effects as measured by the ARCI-LSD scale. The most relevant differences between the two drugs were the significant increases in the HRS-perception and HRS-volition subscales observed for ayahuasca only and which reflect modifications in perception and increased impairment, respectively. The overall pattern of subjective effects induced by ayahuasca replicates results found by our group in a previous study (Riba et al. 2003).

Regarding sleep measures, $d$-amphetamine caused a clear deterioration of subjective sleep quality and objective sleep measures, delaying sleep initiation, disrupting sleep maintenance, increasing light sleep, and decreasing the duration of REM sleep and the number of non-REM and REM cycles. These effects are in line with the welldocumented effects of amphetamine on sleep. This compound and its derivatives suppress REM sleep, and as the doses rise, vigilance is increased and sleep continuity is disturbed (Saletu et al. 1989).

Ayahuasca, on the other hand, did not induce a deterioration of sleep, and no significant effects on sleep initiation or maintenance variables were evidenced. However, like $d$-amphetamine, ayahuasca increased stage 2, decreased REM stage duration and showed a trend to increase REM latency. Furthermore, we observed decreases in the number of non-REM and REM periods and increases in the average duration of non-REM periods and sleep cycles, but these were of less magnitude than after $d$-amphetamine. Also in contrast with $d$-amphetamine, no subjectively measured deterioration was observed compared to placebo.

As evidenced by results in the present and prior (Riba et al. 2003) studies, psychedelics have the capacity to induce increases in activation that can be measured by self-report questionnaires and by EEG (Riba et al. 2002). We had thus postulated that both ayahuasca and $d$-amphetamine would impair sleep initiation and maintenance variables and would suppress REM. The mentioned trend to increase REM latency and the significant decrease in duration were in fact the only common effects observed by means of PSG. In this respect, it is worth mentioning that Gouzoulis et al. (1992) reported the complete suppression of REM after the nighttime administration of MDE, a compound with a chemical structure related to both amphetamines and psychedelic phenylethylamines.

To our knowledge, the sleep effects of pharmacologically closer compounds, i.e., the classical serotonergic psychedelics, have been studied in very few reports, most of which were published in the 1960s. Muzio et al. (1966) administered LSD in doses ranging from 0.08 to $73 \mu \mathrm{g} / \mathrm{kg}$ to 12 volunteers on a total of 36 nights and compared the data obtained with that from 69 control nights in the same subjects. The drug was administered orally just before sleep or after $1 \mathrm{~h}$ of sleep. These authors found LSD increased the duration of the first or second REM period. They also observed that when an abnormal excess of REM sleep had been induced early in the night there was a below-normal amount of REM sleep during the second half of the night (a kind of reverse 'rebound' within the same night). This acute facilitation of the REM stage in humans was also reported by Green (1965) and by Torda (1968). Such findings clearly differ from those obtained in the present study. However, in the mentioned studies, LSD-induced REM increases were always observed after the immediate administration of the compound, whereas in our study ayahuasca was administered at 12:00 noon. Given the complex chemical nature of ayahuasca, other alkaloids besides DMT may have played a role in the effects observed on REM. While harmine, an abundant and pharmacologically potent $\beta$-carboline, appears to undergo an intense first-pass metabolization, substantial levels of THH can be measured in plasma after oral ayahuasca (Riba et al. 2003). THH is a weaker MAO inhibitor than harmine but a stronger serotonin reuptake inhibitor (Buckholtz and Boggan 1977a, b). Reversible MAO inhibitors such as moclobemide (Blois and Gaillard 1990) and selective serotonin reuptake inhibitors (SSRI), such as paroxetine (Hicks et al. 2002), have all been mainly characterized by their ability to decrease REM sleep and to increase stage 2 . It is interesting to note that the sleep effects after SSRIs have been reported to be more evident after morning than after evening drug administration (Barbanoj et al. 2005).

Despite the presence of MAOIs and SSRIs in ayahua$s c a$, its acute pharmacological effects in humans are those of the classical serotonergic psychedelics acting at the $5-\mathrm{HT}_{1 \mathrm{~A}}$ and $5-\mathrm{HT}_{2 \mathrm{~A} / \mathrm{C}}$ sites. The role of these receptors in sleep physiology has been the subject of many studies over the last 40 years. The electrical activity of raphe neurons and the release of 5-HT are increased during waking and decreased during sleep (McGinty and Harper 1976). The available evidence indicates a role for $5-\mathrm{HT}_{1 \mathrm{~A}}$ receptors on REM sleep regulation and for $5-\mathrm{HT}_{2 \mathrm{~A} / \mathrm{C}}$ receptors in SWS regulation. Thus, selective activation of somatodendritic $5-\mathrm{HT}_{1 \mathrm{~A}}$ receptors in the dorsal raphe induces an increase of REM sleep, although activation of the postsynaptic $5-\mathrm{HT}_{1 \mathrm{~A}}$ 
receptors at the level of cholinergic neurons located in tegmentum nuclei decreases REM sleep occurrence (reviewed in Monti and Monti (2000)). 5-HT $1 \mathrm{~A}$ agonists have been shown to suppress REM sleep (Driver et al. 1995; Gillin et al. 1994). Regarding SWS, drugs antagonising $5-\mathrm{HT}_{2 \mathrm{~A}}$ or $5-\mathrm{HT}_{2 \mathrm{C}}$ demonstrate an enhancing effect on SWS (Landolt et al. 1999; Sharpley et al. 1994), whereas $5-\mathrm{HT}_{2 \mathrm{C}}$ agonists appear to lower SWS (Katsuda et al. 1993).

Spectral analysis showed that $d$-amphetamine leads to increases in power in the high-frequency range (higher than $15 \mathrm{~Hz}$ ), an effect mainly observed during stage 2. In addition, the amount of SWA in the first night cycle was also reduced. To our knowledge, there are no published data on $d$-amphetamine effects on night EEG power spectra. However, the above effects could be expected if we take into account the alerting pattern associated with the morning intake of the $d$-amphetamine. The first effect would be related to the vigilance promoting effects associated to increases in power in the higher frequencies (Coull 1998). The second effect would be related to attenuation of sleep propensity associated with wakefulness (Johns 2002). Similar EEG power spectra changes have been reported after caffeine $200 \mathrm{mg}$ intake in the morning (Landolt et al. 1995).

Ayahuasca also showed increases in power in the high frequencies, although these were limited to the 15-20 frequency range. In contrast with $d$-amphetamine, an increase in slow-wave power was observed in the first night cycle. This finding was unexpected, given the SWS decreasing effects that have been associated with $5-\mathrm{HT}_{2}$ agonism (Katsuda et al. 1993). From a neurochemical perspective, these results could be explained by the agonist properties of DMT at the 5-HT $1 \mathrm{~A}$ sites (Seifritz et al. 1996) or through a functional desensitization of the 5- $\mathrm{HT}_{2}$ (Saucier et al. 1998). Activation of $5-\mathrm{HT}_{1 \mathrm{~A}}$ receptors seems to result in a decrease of neural activity at $5-\mathrm{HT}_{2}$ sites. This might be because of either activation of presynaptic autoreceptors within the dorsal raphe nucleus leading to a decrease of activity at postsynaptic projection sites (Sprouse and Aghajanian 1987) and/or activation of postsynaptic $5-\mathrm{HT}_{1 \mathrm{~A}}$ receptors which would exert a modulatory inhibition of $5-\mathrm{HT}_{2}$ receptors (Araneda and Andrade 1991). An alternative explanation is that after the acute effects of ayahuasca, 'sleep pressure' is increased. The increases observed in SWS are typical of certain situations. After sleep deprivation, SWS activity increases are observed limited to the first night cycle (Borbély et al. 1981). Similarly, according to a recent meta-analysis (Driver and Taylor 2000), physical exercise has also been found to induce increases in SWS, reductions in REM and increases in REM latency. The changes observed in SWS could reflect a reaction to the physical and mental stress induced by the drug, as tiredness is frequent after ayahuasca and cortisol levels are augmented in the course of the experience (Callaway et al. 1999).

In summary, the present results did not evidence a deterioration of sleep quality after daytime consumption of ayahuasca. Sleep architecture showed ayahuasca to inhibit REM and spectral analysis demonstrated increases in slowwave activity in the first night cycle. Results suggest an interaction between serotonergic psychedelics and brain circuits modulating REM and SWS.

Acknowledgements The authors thank the staff at the Centre d'Investigació de Medicaments de l'Institut de Recerca de l'Hospital de la Santa Creu i Sant Pau, in particular Adelaida Morte, Llúcia Benito, David Martínez and Liria da Graça for their technical assistance during data collection and Angeles Funes for copy-editing the manuscript. The present research complies with Spanish law. This study was supported by a grant from the Spanish Ministry of Education and Science (SAF 2002-02746) and by the Spanish Ministry of Health, Instituto de Salud Carlos III, RETICS RD06/ 0011 (REM-TAP Network).

\section{References}

Aeschbach D, Borbély AA (1993) All-night dynamics of the human sleep EEG. J Sleep Res 2:70-81

Araneda R, Andrade R (1991) 5-Hydroxytryptamine2 and 5-hydroxytryptamine $1 \mathrm{~A}$ receptors mediate opposing responses on membrane excitability in rat association cortex. Neuroscience 40: 399-412

Barbanoj MJ, Clos S, Romero S, Morte A, Gimenez S, Lorenzo JL, Luque A, Dal-Re R (2005) Sleep laboratory study on single and repeated dose effects of paroxetine, alprazolam and their combination in healthy young volunteers. Neuropsychobiology $51: 134-147$

Blois R, Gaillard JM (1990) Effects of moclobemide on sleep in healthy human subjects. Acta Psychiatr Scand Suppl 360:73-75

Borbély AA, Baumann F, Brandeis D, Strauch I, Lehmann D (1981) Sleep deprivation: effect on sleep stages and EEG power density in man. Electroencephalogr Clin Neurophysiol 51:483-495

Borbély AA, Mattmann P, Loepfe M, Strauch I, Lehmann D (1985) Effect of benzodiazepine hypnotics on all-night sleep EEG spectra. Hum Neurobiol 4:189-194

Buckholtz NS, Boggan WO (1977a) Inhibition by beta-carbolines of monoamine uptake into a synaptosomal preparation: structureactivity relationships. Life Sci 20:2093-2099

Buckholtz NS, Boggan WO (1977b) Monoamine oxidase inhibition in brain and liver produced by beta-carbolines: structure-activity relationships and substrate specificity. Biochem Pharmacol 26:1991-1996

Callaway JC, McKenna DJ, Grob CS, Brito GS, Raymon LP, Poland RE, Andrade EN, Andrade EO, Mash DC (1999) Pharmacokinetics of Hoasca alkaloids in healthy humans. J Ethnopharmacol $65: 243-256$

Coull JT (1998) Neural correlates of attention and arousal: insights from electrophysiology, functional neuroimaging and psychopharmacology. Prog Neurobiol 55:343-361

Deliganis AV, Pierce PA, Peroutka SJ (1991) Differential interactions of dimethyltryptamine (DMT) with 5-HT1A and 5-HT2 receptors. Biochem Pharmacol 41:1739-1744

Driver HS, Taylor SR (2000) Exercise and sleep. Sleep Med Rev 4:387-402 
Driver HS, Flanigan MJ, Bentley AJ, Luus HG, Shapiro CM, Mitchell D (1995) The influence of ipsapirone, a 5-HT1A agonist, on sleep patterns of healthy subjects. Psychopharmacology (Berl) 117:186-192

Feinberg I, Floyd TC (1979) Systematic trends across the night in human sleep cycles. Psychophysiology 16:283-291

Gillin JC, Jernajczyk W, Valladares-Neto DC, Golshan S, Lardon M, Stahl SM (1994) Inhibition of REM sleep by ipsapirone, a 5HT1 A agonist, in normal volunteers. Psychopharmacology (Berl) 116:433-436

Gouzoulis E, Steiger A, Ensslin M, Kovar A, Hermle L (1992) Sleep EEG effects of 3,4-methylenedioxyethamphetamine (MDE; "eve") in healthy volunteers. Biol Psychiatry 32:1108-1117

Green WJ (1965) The effect of LSD on the sleep-dream cycle. An exploratory study. J Nerv Ment Dis 140:417-426

Hicks JA, Argyropoulos SV, Rich AS, Nash JR, Bell CJ, Edwards C, Nutt DJ, Wilson SJ (2002) Randomised controlled study of sleep after nefazodone or paroxetine treatment in out-patients with depression. Br J Psychiatry 180:528-535

Johns MW (2002) Sleep propensity varies with behaviour and the situation in which it is measured: the concept of somnificity. J Sleep Res 11:61-67

Katsuda Y, Walsh AE, Ware CJ, Cowen PJ, Sharpley AL (1993) metaChlorophenylpiperazine decreases slow-wave sleep in humans. Biol Psychiatry 33:49-51

Lamas X, Farre M, Llorente M, Cami J (1994) Spanish version of the 49-item short form of the Addiction Research Center Inventory (ARCI). Drug Alcohol Depend 35:203-209

Landolt HP, Werth E, Borbely AA, Dijk DJ (1995) Caffeine intake (200 mg) in the morning affects human sleep and EEG power spectra at night. Brain Res 675:67-74

Landolt HP, Meier V, Burgess HJ, Finelli LA, Cattelin F, Achermann P, Borbely AA (1999) Serotonin-2 receptors and human sleep: effect of a selective antagonist on EEG power spectra. Neuropsychopharmacology 21:455-466

Martin WR, Sloan JW, Sapira JD, Jasinski DR (1971) Physiologic, subjective, and behavioral effects of amphetamine, methamphetamine, ephedrine, phenmetrazine, and methylphenidate in man. Clin Pharmacol Ther 12:245-258

McGinty DJ, Harper RM (1976) Dorsal raphe neurons: depression of firing during sleep in cats. Brain Res 101:569-575

Monti JM, Monti D (2000) Role of dorsal raphe nucleus serotonin 5HT1A receptor in the regulation of REM sleep. Life Sci 66:1999-2012

Morgan MJ (2000) Ecstasy (MDMA): a review of its possible persistent psychological effects. Psychopharmacology (Berl) $152: 230-248$

Muzio JN, Roffwarg HP, Kaufman E (1966) Alterations in the nocturnal sleep cycle resulting from LSD. Electroencephalogr Clin Neurophysiol 21:313-324

Preud'homme XA, Lanquart JP, Mendlewicz J, Linkowski P (2000) Characteristics of spontaneous sleep with varying NREMS
Episodes in healthy men: implication for delta activity homeostasis. Sleep 23:193-203

Rechtschaffen A, Kales A (1968) Techniques and scoring system for sleep stages in human subjects. US Government Printing Office, Washington, DC, USA

Riba J, Rodriguez-Fornells A, Strassman RJ, Barbanoj MJ (2001) Psychometric assessment of the Hallucinogen Rating Scale. Drug Alcohol Depend 62:215-223

Riba J, Anderer P, Morte A, Urbano G, Jane F, Saletu B, Barbanoj MJ (2002) Topographic pharmaco-EEG mapping of the effects of the South American psychoactive beverage ayahuasca in healthy volunteers. Br J Clin Pharmacol 53:613-628

Riba J, Valle M, Urbano G, Yritia M, Morte A, Barbanoj MJ (2003) Human pharmacology of ayahuasca: subjective and cardiovascular effects, monoamine metabolite excretion, and pharmacokinetics. J Pharmacol Exp Ther 306:73-83

Riba J, Romero S, Grasa E, Mena E, Carrio I, Barbanoj MJ (2006) Increased frontal and paralimbic activation following ayahuasca, the pan-Amazonian inebriant. Psychopharmacology (Berl) 186:93-98

Saletu B, Wesseley P, Grünberger J, Schultes M (1987) Erste klinische Erfahrungen mit einem neuen Schlafanstossenden Benzodiazepin Cinolazepam mittels eines Selbstbeurteilungsbögens für Schlafund Aufwachqualität (SSA). Neuropsychiatrie 1:169-176

Saletu B, Frey R, Krupka M, Anderer P, Grunberger J, Barbanoj MJ (1989) Differential effects of a new central adrenergic agonistmodafinil-and D-amphetamine on sleep and early morning behaviour in young healthy volunteers. Int J Clin Pharmacol Res 9:183-195

Saucier C, Morris SJ, Albert PR (1998) Endogenous serotonin-2A and $-2 \mathrm{C}$ receptors in Balb/c-3T3 cells revealed in serotonin-free medium: desensitization and down-regulation by serotonin. Biochem Pharmacol 56:1347-1357

Schlösser R, Roschke J, Rossbach W, Benkert O (1998) Conventional and spectral power analysis of all-night sleep EEG after subchronic treatment with paroxetine in healthy male volunteers. Eur Neuropsychopharmacol 8:273-278

Schultes RE, Hofmann A (1987) Plants of the gods: origins of hallucinogenic use. van der Marck Editions, New York

Seifritz E, Moore P, Trachsel L, Bhatti T, Stahl SM, Gillin JC (1996) The 5-HT1A agonist ipsapirone enhances EEG slow wave activity in human sleep and produces a power spectrum similar to 5-HT2 blockade. Neurosci Lett 209:41-44

Sharpley AL, Elliott JM, Attenburrow MJ, Cowen PJ (1994) Slow wave sleep in humans: role of 5-HT2A and 5-HT2C receptors. Neuropharmacology 33:467-471

Sprouse JS, Aghajanian GK (1987) Electrophysiological responses of serotoninergic dorsal raphe neurons to 5-HT1A and 5-HT1B agonists. Synapse 1:3-9

Torda C (1968) Contribution to serotonin theory of dreaming (LSD infusion). N Y State J Med 68:1135-1138 